\title{
Transforming the Learning Experience of Non-Traditional Students in an Online CS1 Course through Peer-Instruction
}

\author{
Farzana Rahman \\ Electrical Engineering and Computer Science \\ Syracuse University \\ Syracuse, NY, USA \\ frahma02@syr.edu
}

\author{
Tiana Solis \\ Computing and Information Sciences \\ Florida International University \\ Miami, FL, USA \\ tsolis@fiu.edu
}

\begin{abstract}
In the 21st century, Computer science (CS) academic programs are becoming as diverse and innovative as computer science itself. Due to the increasing number of jobs and national demands for more computing professionals, we see a surge of non-traditional students (aged over 25), entering the CS1 course, who already have a degree in a different discipline and work either full-time or part-time. These students have very low retention rate beyond CS1 course. We researched at a large metropolitan public research university, Florida International University (FIU), where we have designed an online CS1 course, integrating peer-instruction, to addresses the divergent background of our student population so they can thrive in computing major/minor, beyond CS1 course. In this poster, we report our findings on how the learning experience of non-traditional students is impacted by the peer-instruction integrated in the online CS1 course.
\end{abstract}

\section{CCS CONCEPTS}

- Social and professional topics $\rightarrow$ Computing education programs.

\section{KEYWORDS}

Coding; non-traditional; CS1; active learning; peer-instruction

\section{INTRODUCTION}

In today's fast-paced modern world, students are looking for academic programs that meet their needs with very full lives and time-dependent jobs and family responsibilities. Online programs offer the flexibility that students are looking for while maintaining the universities' academic commitment. Interestingly, recently computing programs started to open doors to non-traditional students (aged over 25), who prefer an option for a more flexible learning environment and schedule and tend to enroll in online courses at large.

Non-traditional students have different motivations and goals, as well as barriers compared to most traditional students. For nontraditional students, going back to school requires more planning and lifestyle reassessment than it does for traditional students. They may have families or spouses, full-time jobs, and mortgages Permission to make digital or hard copies of part or all of this work for personal or classroom use is granted without fee provided that copies are not made or distributed for profit or commercial advantage and that copies bear this notice and the full citation on the first page. Copyrights for third-party components of this work must be honored. For all other uses, contact the Owner/Author.

SIGCSE '20, March 11-14, 2020, Portland, OR, USA

(C) 2020 Copyright is held by the owner/author(s).

ACM ISBN 978-1-4503-6793-6/20/03.

https://doi.org/10.1145/3328778.3372591 they are responsible for. Non-traditional students are also more likely to leave school due to conflicting responsibilities (work, parenting, caring for an elderly parent), are less likely to complete their CS degree, and have lower retention rates compared to traditional students. Similarly, when non-traditional students enroll in a CS1 course, with or without the intention of getting a computing degree, we hypothesize that they tend to have differing goals and motivations, as well as expectations. As online learning and non-traditional students' enrollment continues to see significant growth in computing, it is important to pursue answers to key questions that relate to how peer instruction affect their persistence and success in computing.

\section{CONTRIBUTIONS}

To find answers to these questions, we conducted a study at a large metropolitan public research university, Florida International University (FIU), where $30 \%$ of the students are nontraditional students. However, the online CS1 course, which took part in our study, usually consists of 70-75 percent of nontraditional students with very low retention and academic success rate. we report our findings based on a study done over the last 5 semesters consisting of 250 students. Our findings report why a majority of the non-traditional students choose the online CS1 section, many of which relate to convenience, personal learning style, and degree of familiarity with the course material. We investigate if peer-instruction benefit non-traditional students to better their performance and persistence in an online CS1 course. The research questions for this study are:

RQ1. Are non-traditional students from peer-instruction section more likely to perform better in the exam and course?

RQ2. Are non-traditional students from peer-instruction section more likely to continue in computing discipline?

RQ3. Does student performance differ in the traditional online CS1 course vs. peer-instruction integrated online CS1 course?

Preliminary Results: Upon institutional review board (IRB) approval, preliminary data were collected starting from spring 2018. Our final survey included a question about overall quality of students' learning experience in this course, to which close to $77 \%$ answered positively. Close to $65 \%$ student reported they were satisfied with the sense of community, created through peer instruction, which were further backed up by many free form comments. We also asked them if having access to peerinstruction through a discussion forum was useful for their learning programming, to which $72 \%$ responded positively. 